\title{
Diisopinocampheylhaloboranes as Stereoselective Reducing Agents
}

\author{
Jin Soon Cha," Oh Oun Kwon, Kwang Woo Lee, ${ }^{\dagger}$ and Jong Mi Kim ${ }^{*}$ \\ Department of Chemistry and Institute of Natural Sciences, Yeungnam University, Gyongsan 712-749, Korea \\ *E-mail: jscha@yu.ac.kr \\ ${ }^{\dagger}$ Department of Health of Herb, Taegue Science College, Daegue 702-723, Korea \\ ${ }^{\ddagger}$ Division of Cosmetic, Kyongbuk College of Science, Chilgok 718-850, Korea \\ Received January 6, 2005
}

Key Words : Stereoselective reduction, Cyclic ketones, $B$-Diisopinocampheylhaloborane, MPV type reduction

Chiral diisopinocampheylchloroborane $\left({ }^{\mathrm{d}} \mathrm{Ipc}_{2} \mathrm{BCl}\right.$ and $\left.{ }^{1} \mathrm{Ipc}_{2} \mathrm{BCl}\right)^{1}$ has proven to be extremely efficient for the chiral reduction of aralkyl ketones, ${ }^{2,4,5} \alpha$-tertiary alkyl ketones, ${ }^{3,4}$ and $\alpha, \beta$-acetylenic ketones. ${ }^{6}$ In addition to that, the reagent appears to be an excellent chemo- and regioselective reducing agent in the reduction of carbonyl compounds. ${ }^{7-9}$ Most organic functional groups, except for aldehydes, ketones $^{2-9}$ and epoxides, ${ }^{10}$ are compatible with the reagent. ${ }^{8}$ Moreover, the ready availability of both the enantiomers (naturally occurring), simple reaction conditions, easy workup procedure, and complete recovery of the chiral auxiliary $\alpha$-pinene ${ }^{10}$ make this reagent especially attractive. The mechanism of the reduction is explained via a cyclic boatlike transition state. ${ }^{4,7-9}$ This fascinating reagent attracted us to investigate its general reducing characteristics in details. In the course of exploration of its selectivity, we found that ${ }^{\mathrm{d}} \mathrm{Ipc}_{2} \mathrm{BCl}$ reduces cyclic ketones in a considerable degree of stereoselectivity. Such results led us to consider the role of both isopinocampheyl moiety (Ipc-) and halogen substituent in $\mathrm{Ipc}_{2} \mathrm{BX}$ in the stereoselective reduction of cyclic ketones: the steric size of halogen atom might play an important role in such a reduction. Accordingly, we examined a series of diisopinocampheylhaloboranes ( $\operatorname{Ipc}_{2} \mathrm{BX}$, where $\mathrm{X}=\mathrm{Cl}, \mathrm{Br}, \mathrm{I})$, as the stereostructure of isopinocampheyl group being fixed, for their stereoselectivity in the reduction of representative monocyclic and bicyclic ketones. ${ }^{11}$

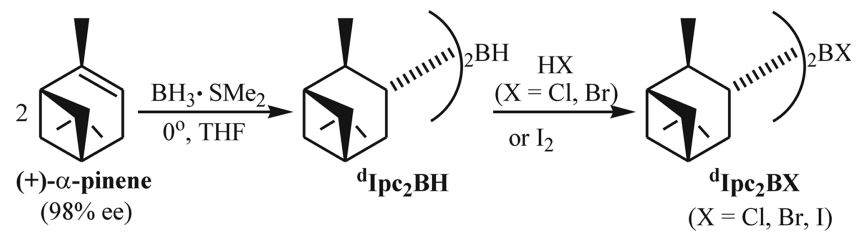

As Table 1 shows, the halogen substituent in ${ }^{\mathrm{d}} \mathrm{Ipc}_{2} \mathrm{BX}$ plays an important role in the selective reduction of typical cyclic ketones as expected. The stereoselectivity increased dramatically with increasing steric size of the substituent. For example, in the reduction of 4-methylcyclohexanone at $-30{ }^{\circ} \mathrm{C}{ }^{\mathrm{d}} \mathrm{Ipc}_{2} \mathrm{BCl}$ affords $74 \%$ cis-4-methylcyclohexanol, the less stable isomer. However, the introduction of the bromo group instead of chloro one exerts a tremendous stereoselectivity enhancement (to 91.5\%). Furthermore, the stereoselectivity of the iodo derivative reaches up to $98 \%$. Generally, the bromo derivative achieves a relatively very high stereoselective reduction, compared to other results done by several conventional reagents. However, the iodo derivative appears to be a really ideal stereoselective reducing agent, showing an essentially $100 \%$ selectivity in the reduction of representative cyclic ketones at $-30{ }^{\circ} \mathrm{C}$. It is noteworthy to note that ${ }^{1} \mathrm{Ipc}_{2} \mathrm{BCl}$, prepared from (-)- $\alpha$ pinene, shows a similar selectivity as ${ }^{\mathrm{d}} \mathrm{Ipc}_{2} \mathrm{BCl}$ does. On the other hand, the selectivity achieved by ${ }^{\mathrm{dl}} \mathrm{Ipc}_{2} \mathrm{BBr}$, prepared from a racemate of $\alpha$-pinene, is significantly lower than that by ${ }^{\mathrm{d}} \mathrm{Ipc}_{2} \mathrm{BBr}$. For example, in the reduction of norcamphor at $0^{\mathrm{O}}{ }^{\mathrm{d}} \mathrm{Ipc}_{2} \mathrm{BBr}$ gave endo-norborneol in an essentially $100 \%$ selectivity, whereas ${ }^{\mathrm{dl}} \mathrm{Ipc}_{2} \mathrm{BBr}$ afforded the less stable isomer in a ratio of $76 \%$.

Although $\mathrm{Ipc}_{2} \mathrm{BI}$, particularly among $\mathrm{Ipc}_{2} \mathrm{BX}$, achieves an essentially $100 \%$ stereoselectivity in the reduction of cyclic ketones, the reagent possesses a drawback in producing alcohols. The yields of alcohols in the reduction of cyclic ketones with $\mathrm{Ipc}_{2} \mathrm{BI}$ were significantly low. Several experiments with varying reaction conditions (ie., an increase in the ratio of reagent to ketone, a longer reaction time, or an increase in the concentration of reagent) were carried out in order to increase the yields of alcohols: no significant increase in the yield was realized and the starting ketone was recovered. It is believed that the hydride transfer from the isopinocampheyl group of $\mathrm{Ipc}_{2} \mathrm{BI}$ competes with the iodide transfer from $\mathrm{Ipc}_{2} \mathrm{BI}$ to the carbonyl carbon; the iodinated product is then converted into the starting ketone upon hydrolysis.

$\mathrm{Ipc}_{2} \mathrm{BI}$, particularly among $\mathrm{Ipc}_{2} \mathrm{BX}$, achieves an essentially perfect stereoselective reduction of representative cyclic ketones to afford the less stable alcohol isomers exclusively. The disadvantage of this reaction as a preparative method is the low yield of the alcohol product and, hence, the use of excess reactants is necessary to obtain 
Table 1. Stereoselective Reduction of Representative Cyclic Ketones with $\mathrm{Ipc}_{2} \mathrm{BX}$ in Pentane ${ }^{a}$

\begin{tabular}{|c|c|c|c|c|c|c|c|}
\hline \multirow[b]{2}{*}{ ketone } & \multirow[b]{2}{*}{ temp. } & \multicolumn{2}{|l|}{$\mathrm{Ipc}_{2} \mathrm{BCl}$} & \multicolumn{2}{|c|}{$\mathrm{Ipc}_{2} \mathrm{BBr}$} & \multicolumn{2}{|c|}{$\mathrm{Ipc}_{2} \mathrm{BI}$} \\
\hline & & $\begin{array}{l}\text { ratio of less } \\
\text { stable isomer } \\
(\%)^{b}\end{array}$ & $\begin{array}{l}\text { yield of } \\
\text { alcohol } \\
(\%)^{b}\end{array}$ & $\begin{array}{c}\text { ratio of less } \\
\text { stable isomer } \\
(\%)^{b}\end{array}$ & $\begin{array}{l}\text { yield of } \\
\text { alcohol } \\
(\%)^{b}\end{array}$ & $\begin{array}{c}\text { ratio of less } \\
\text { stable isomer } \\
(\%)^{b}\end{array}$ & $\begin{array}{c}\text { yield of } \\
\text { alcohol } \\
(\%)^{b}\end{array}$ \\
\hline \multirow{3}{*}{$\begin{array}{l}\text { 2-methyl- } \\
\text { cyclohexanone }\end{array}$} & 25 & & & & & 55 & 60 \\
\hline & 0 & 34 & 99 & 93.5 & 86 & 94 & 55 \\
\hline & -30 & 47 & 95 & $>99.9$ & 84 & $>99.9$ & 50 \\
\hline \multirow{3}{*}{$\begin{array}{l}\text { 3-methyl- } \\
\text { cyclohexanone }\end{array}$} & 25 & & & & & 65 & 80 \\
\hline & 0 & $89(85)^{c}$ & $99(86)^{c}$ & 89.5 & 80 & $98(98)^{e}$ & $50(60)^{e}$ \\
\hline & -30 & 92 & 95 & 94 & 80 & 99.9 & 45 \\
\hline \multirow{2}{*}{$\begin{array}{l}\text { 4-methyl- } \\
\text { cyclohexanone }\end{array}$} & 0 & $63(62)^{c}$ & $99(86)^{c}$ & 80 & 70 & 92 & 60 \\
\hline & -30 & 74 & 99 & 91.5 & 70 & 98 & 55 \\
\hline \multirow{2}{*}{$\begin{array}{l}\text { 4-t-butyl- } \\
\text { cyclohexanone }\end{array}$} & 0 & 80 & 75 & 87 & 64 & $98(60)^{f}$ & $98(65)^{f}$ \\
\hline & -30 & 90 & 70 & 91 & 60 & $99.8(56)^{g}$ & $56(60)^{g}$ \\
\hline \multirow{3}{*}{$\begin{array}{l}\text { 3,3,5-trimethyl- } \\
\text { cyclohexanone }\end{array}$} & 25 & & & & & 80 & 91 \\
\hline & 0 & 97 & 100 & 98 & 90 & $>99.9$ & 90 \\
\hline & -30 & 98 & 99 & 99 & 90 & $>99.9$ & 86 \\
\hline \multirow[t]{3}{*}{ norcamphor } & 25 & & & $>99.9$ & 95 & $>99.9$ & 65 \\
\hline & 0 & $91(92)^{c}$ & $95(100)^{c}$ & $>99.9(76)^{d}$ & $90(95)^{d}$ & $>99.9(>99.9)^{f}$ & $60(65)^{f}$ \\
\hline & -30 & 95.5 & 90 & $>99.9$ & 89 & $>99.9(>99.9)^{g}$ & $50(52)^{g}$ \\
\hline \multirow[t]{3}{*}{ camphor } & 25 & & & 98 & 65 & 98 & 45 \\
\hline & 0 & 81 & 72 & $>99.9(97)^{d}$ & $65(60)^{d}$ & $>99.9$ & 40 \\
\hline & -30 & 99.5 & 70 & $>99.9$ & 60 & $>99.9(99.9)^{g}$ & $30(32)^{g}$ \\
\hline
\end{tabular}

${ }^{a}$ Reagents were prepared from (+)- $\alpha$-pinene (98\% ee), except where otherwise indicated. ${ }^{b} \mathrm{~A} 2: 1$ ratio for reagent $(1.25 \mathrm{M}):$ ketone was utilized; reacted for $24 \mathrm{~h}$ with $\mathrm{Ipc}_{2} \mathrm{BCl}$, and $48 \mathrm{~h}$ with $\mathrm{Ipc}_{2} \mathrm{BBr}$ or $\mathrm{Ipc}_{2} \mathrm{BI}$. ${ }^{c}$ Data obtained by using ${ }^{\mathrm{I}} \mathrm{Ipc}_{2} \mathrm{BX}$ prepared from $(-)-\alpha$-pinene $\left(98 \%\right.$ ee). ${ }^{d} \mathrm{Data}$ obtained using ${ }^{d l} \mathrm{Ipc}_{2} \mathrm{BX}$ prepared from ( $( \pm)-\alpha$-pinene. ${ }^{e} \mathrm{~A} 4: 1$ ratio for reagent : ketone was utilized. ${ }^{f} \mathrm{~A}$ solution of $3.3 \mathrm{M}$ was used. ${ }^{g}$ Reacted for 7 days.

enough amount of product alcohols. $\mathrm{Ipc}_{2} \mathrm{BX}$ is extremely mild: almost all of organic functionalities are compatible except for aldehydes, ketones and epoxides. This mildness adds another advantage to this reagent applicable to polyfunctional molecules.

\section{Experimental Section}

Techniques for handling air-sensitive compounds have been previously described. ${ }^{12}{ }^{11} \mathrm{~B}$ NMR was recorded on 300$\mathrm{MHz}$ Bruker instrument. GC analysis was done on a Hewlett-Packard 5790A gas Chromatograph having a flame ionization detector, integrated with a Hewlett-Packard 3390 integrator/plotter. GC columns, 1/8 in. $\times 12 \mathrm{ft}$, were packed with 10\% Carbowax $20 \mathrm{M}$ on Supelcoport (100-120 mesh) or $15 \%$ THEED on Supelcoport (100-120 mesh).

Borane-methyl sulfide (BMS) and $\alpha$-pinene (98\% ee) were obtained from the Aldrich Chemcal Co. The ketones were obtained from the Aldrich Chemical Co. or Fluka Chemie AG and were used as received. Anhydrous ethereal hydrogen chloride and hydrogen bromide were prepared by using a Brown automatic gasimeter.

Preparation of Diisopinocampheylhaloborane $\left(\operatorname{Ipc}_{2} \mathbf{B X}\right){ }^{14}$ The procedure for preparation of $\mathrm{Ipc}_{2} \mathrm{BCl}$ is illustrative. Diisopinocamphylborane ( $\left.\mathrm{Ipc}_{2} \mathrm{BH}\right)$, prepared from $(+)-\alpha-$ pinene $(220 \mathrm{mmol})$ and BMS $(100 \mathrm{mmol})$ in THF $(96 \mathrm{~mL})$ at $0^{\circ}$ by the reported precedure, ${ }^{13}$ was suspended in diethyl ether $(\mathrm{EE} ; 50 \mathrm{~mL})$ in a $250-\mathrm{mL}$ round-bottom flask containing a magnetic stirring bar and fitted with a septumcapped sidearm and a connecting tube. Dry $\mathrm{HCl}$ in $\mathrm{EE}(1$ equiv, calculated for the amount of $\mathrm{Ipc}_{2} \mathrm{BH}$ ) was added. After being stirred for $15 \mathrm{~min}$ at $-78^{\circ}$, the reaction mixture was warmed to $0^{\circ}$ and stirred at that temperature until all of the solid dissolved and gas evolution ceased. The EE was pumped off and $50 \mathrm{~mL}$ of pentane was added. ${ }^{11} \mathrm{~B}$ NMR showed a singlet at $\delta 75 \mathrm{ppm}$. Similary, $\mathrm{Ipc}_{2} \mathrm{BBr}$ was prepared by using dry $\mathrm{HBr}$ in EE. ${ }^{11} \mathrm{~B} \mathrm{NMR}$ of a solution of $\mathrm{Ipc}_{2} \mathrm{BBr}$ in pentane showed a singlet at $\delta 75 \mathrm{ppm}$.

$\mathrm{Ipc}_{2} \mathrm{BI}$ was prepared as follows. Into a $250-\mathrm{mL}$ flask containing a freshly-prepared solid of $\mathrm{Ipc}_{2} \mathrm{BH}(50 \mathrm{mmol})$ was added $50 \mathrm{~mL}$ of EE and the flask was immersed into an ice-water bath. To the slurry suspended in EE was added dropwise a $1 \mathrm{M}$ solution of $\mathrm{I}_{2}(25 \mathrm{~mL}, 25 \mathrm{mmol})$ in $\mathrm{CS}_{2}$ and the reaction mixture was stirred at that temperature until all of the solid dissolved and gas evolution completed $(2 \mathrm{~h})$. All the solvents were pumped off and $30 \mathrm{~mL}$ of pentane was added. ${ }^{11} \mathrm{~B}$ NMR showed a singlet at $\delta 74 \mathrm{ppm}$.

Stereoselective Reductions. The following procedure was used to explore the stereoselectivity of these reagents. In an oven-dried, $10 \mathrm{~mL}$ round-bottom flask equipped with a septum-capped sidearm and a magnetic stirring bar was placed $3.2 \mathrm{~mL}$ of a $1.25 \mathrm{M}$ solution of $\mathrm{Ipc}_{2} \mathrm{BI}$ in pentane (4.0 mmol). The flask was maintained at $-30^{\circ}$ by a bath. To this flask was added $0.23 \mathrm{~g}$ of 2-methylcyclohexanone $(2 \mathrm{mmol})$ and the mixture was stirred for $48 \mathrm{~h}$ at $-30^{\circ}$. The reaction mixture was then quenched by addition of $5 \mathrm{~mL}$ of $3 \mathrm{M}$ 
$\mathrm{NaOH}$. The organoborane was oxidized by treatment with $1.4 \mathrm{~mL}$ of $30 \% \mathrm{H}_{2} \mathrm{O}_{2}$. The aqueous layer was saturated with anhydrous $\mathrm{K}_{2} \mathrm{CO}_{3}$ and the organic layer was separated and dried. GC analysis revealed the presence of 50\% 2methylcyclohexanol containing $>99.9 \%$ of the cis isomer and a trace of trans isomer.

Acknowledgment. This work was financially supported by the Korea Research Foundation (KRF-2004-000-10252$0)$.

\section{References}

1. The superscripts ' $d$ ' and ' $l$ ' indicate that the reagents are derived from (+)- and (-)- $\alpha$-pinene, respectively: Joshi, N. N.; Srebnik, M.; Brown, H. C. J. Am. Chem. Soc. 1988, 110, 6246.

2. Chandrasekharan, J.; Ramachandran, P. V.; Brown, H. C. J. Org. Chem. 1985, 50, 5446.

3. Brown, H. C.; Chandrasekharan, J.; Ramachandran, P. V. J. Org. Chem. 1986, 51, 3394.

4. Brown, H. C.; Chandrasekharan, J.; Ramachandran, P. V. J. Am.
Chem. Soc. 1988, 110, 1539.

5. Srebnik, M.; Ramachandran, P. V.; Brown, H. C. J. Org. Chem. 1988, 53, 2916

6. Ramachandran, P. V.; Teodorovic, A. V.; Rangaishenvi, M. V.; Brown, H. C. J. Org. Chem. 1992, 57, 2379.

7. Cha, J. S.; Kim, E. J.; Kwon, O. O.; Kim, J. M. Bull. Korean Chem. Soc. 1994, 15, 1033.

8. Cha, J. S.; Kim, E. J.; Kwon, O. O.; Kim, J. M. Synlett 1995, 331.

9. Cha, J. S.; Kim, E. J.; Kwon, O. O.; Kim, J. M. Bull. Korean Chem. Soc. 1996, 17, 50.

10. Brown, H. C.; Srebnik, M.; Ramachandran, P. V. J. Org. Chem. 1989, 54, 1577.

11. For other related studies on diisopinocampheylalkoxyboranes, see: (a) Cha, J. S.; Jang, S. H.; Kwon, S. Y.; Kwon, O. O. Bull. Korean Chem. Soc. 2004, 25, 603. (b) Cha, J. S.; Nam, H. T.; Jang, S. H.; Kwon, S. Y.; Park, S. J.; Kwon, O. O. Bull. Korean Chem. Soc. 2004, 25, 1948

12. Brown, H. C.; Kramer, G. W.; Levy, A. B.; Midland, M. M. Organic Synthesis via Boranes; Wiley-Interscience: New York, 1975; Chapter 9.

13. Brown, H. C.; Singaram, B. J. J. Org. Chem. 1984, 49, 945.

14. See also the other preparation procedure: Brown, H. C.; Ramachandran, P. V.; Chandrasekharan, J. Heteroatom Chem. $1995,6,117$. 